\title{
VALOR AGREGADO BRUTO DE TUNGURAHUA
}

El indicador macroeconómico que mide el valor añadido realizado por cada sector o industria en el proceso productivo de bienes y servicios finales, realizados en un periodo de tiempo determinado y en un área específica es el valor agregado bruto, este indicador sirve de base para la estimación del Producto Interno Bruto.

De acuerdo a la última información oficial presentada por la Dirección de Estadística Económica del Banco Central del Ecuador, sobre las cuentas regionales desagregadas por cada uno de los cantones que tiene cada provincia en el Ecuador, El total del valor agregado es de 59.013.275,00 miles de dólares al año 2009 , de los cuales las provincias más generadoras de valor es en primer lugar Guayas con el $26,8 \%$, en segundo lugar esta Pichincha con el $24,4 \%$, en la tercera ubicación es Manabí con el $5,7 \%$ y en cuarto lugar con una participación de 5\% es Orellana, mientras que la provincia de Tungurahua aporta con el $2,79 \%$ ubicándose en la posición diez a nivel nacional.

\section{Valor Agregado Bruto, Según Provincias \\ Ã̃̃o 2009}

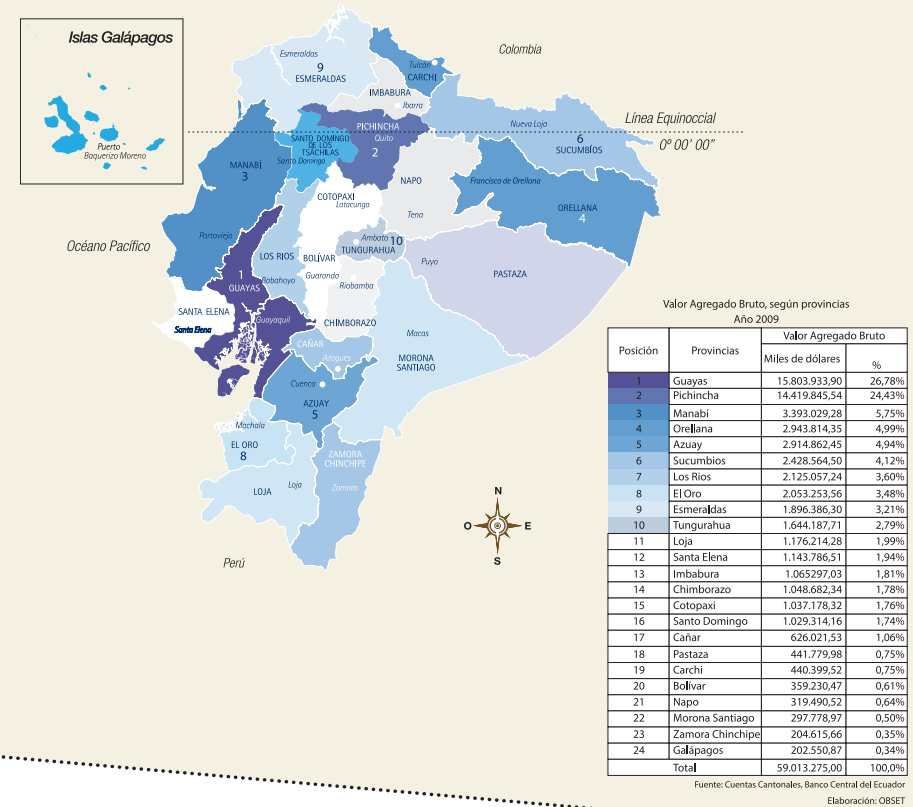

En función de la Planificación Nacional que promueve la Secretaría Nacional de Planificación y Desarrollo SENPLADES, La zona No. 8 (Esmeraldas, Carchi, Imbabura y Sucumbíos) es la que mayor aporta al valor agregado con $13.460 .414,73$ miles de dólares, y la que tiene una menor participación es la zona No. 7 (El Oro, Loja y Zamora Chinchipe) con 3.434.083,50 miles de dólares.

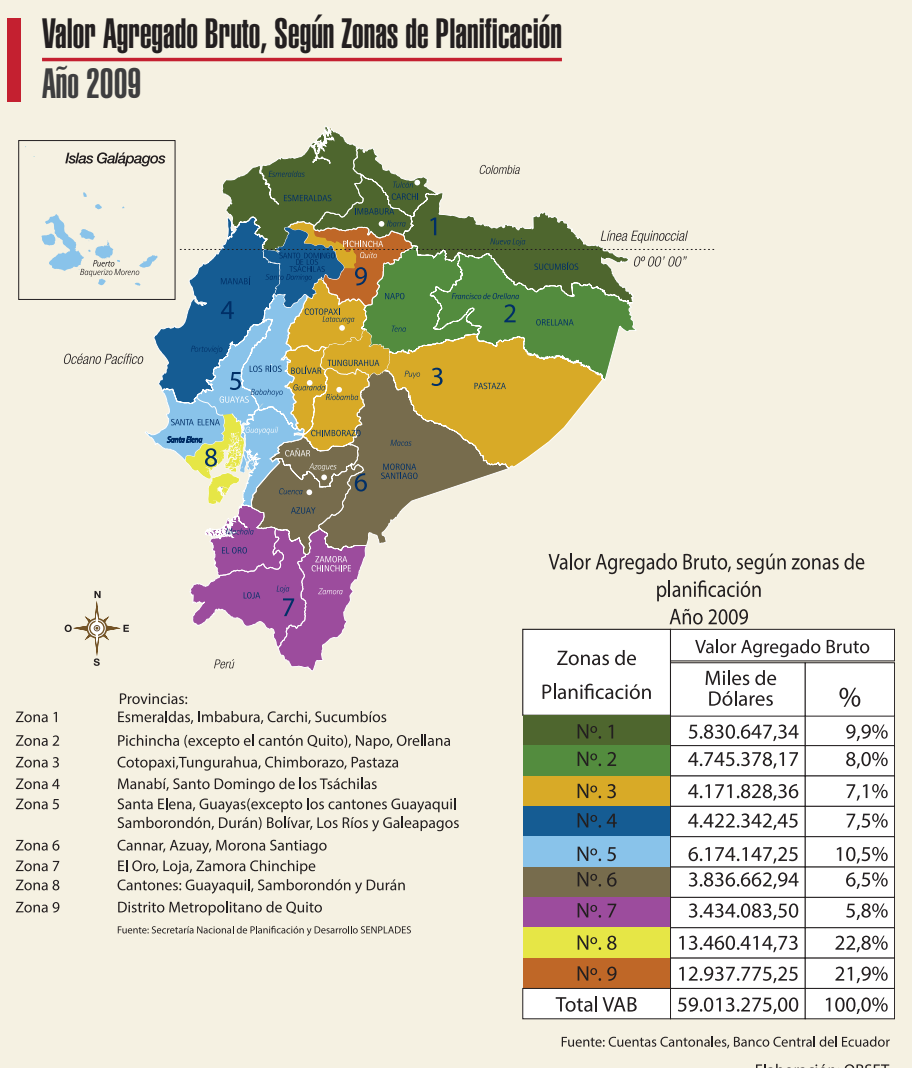

La zona de planificación No. 3 ocupa la séptima posición frente a las demás del Ecuador, con un valor de 4.171.828,36 miles de dólares, en función de su conformación la provincia con más representatividad es Tungurahua con $(39,4 \%)$, después esta Chimborazo $(25,1 \%)$, le sigue Cotopaxi $(24,9 \%)$ y finalmente Pastaza (10,6\%) con respecto al total zonal. 
PARTIGIPAGIÓN AL VALOR AGREEADO BRUTO

\section{ZONA DE PLANIFIBABIIN No. 3}

Aก்̃ 2009

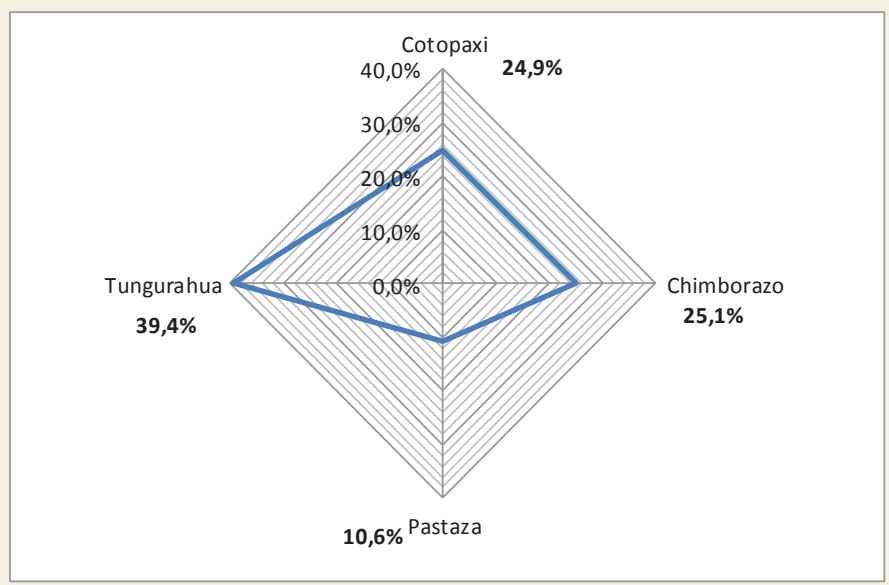

Fuente: Cuentas Cantonales, Banco Central del Ecuador

Elaboración: Personal Técnico Observatorio Económico y Social de Tungurahua

Las industrias consideradas en la metodología del Banco Central para estimar el valor agregado bruto cantonal son catorce que son: Agricultura, ganadería, silvicultura y pesca; Explotación de minas y canteras; Manufactura; Suministro de electricidad y de agua; Construcción; Comercio; Actividades de alojamiento y de comidas; Transporte, información y comunicaciones; Actividades financieras; Actividades profesionales e inmobiliarias; Administración pública; Enseñanza; Salud y Otros servicios, en la provincia de Tungurahua los valores agregados son los siguientes:

\begin{tabular}{|c|c|c|c|c|c|c|}
\hline $\begin{array}{c}\text { ANDS } \\
\text { INDUSTHIAS }\end{array}$ & $\begin{array}{l}\text { VViB } \\
\text { Aino } 2007\end{array}$ & $\%$ & $\begin{array}{l}\text { VAB } \\
\text { Aino } 2008\end{array}$ & $\%$ & $\begin{array}{c}\text { VAB } \\
\text { Aĩo } 2009\end{array}$ & $\%$ \\
\hline Agricultura, ganadería, silvicultura y pesca & 92.540 & $6,8 \%$ & 95.618 & $6,2 \%$ & $\$ \quad 126.040$ & $7,7 \%$ \\
\hline Explotación de minas y canteras & 1.060 & $0,1 \%$ & 1.176 & $0,1 \%$ & 890 & $0,1 \%$ \\
\hline Manufactura & \$ 159.881 & $11,8 \%$ & 184.800 & $12,1 \%$ & $\$ 138.513$ & $8,4 \%$ \\
\hline Suministro de electricidad y de agua & $\$ 107.452$ & $7,9 \%$ & 113.027 & $7,4 \%$ & $\$ \quad 111.827$ & $6,8 \%$ \\
\hline Construcción & $\$ 171.361$ & $12,6 \%$ & 198.955 & $13,0 \%$ & 189.735 & $11,5 \%$ \\
\hline Comercio & $\$ 161.575$ & $11,9 \%$ & 227.509 & $14,8 \%$ & $\$ \quad 245.622$ & $14,9 \%$ \\
\hline Actividades de alojamiento y de comidas & 35.614 & $2,6 \%$ & 37.237 & $2,4 \%$ & 49.320 & $3,0 \%$ \\
\hline Transporte, información y comunicaciones & $\$ 203.963$ & $15,0 \%$ & 230.829 & $15,1 \%$ & 226.744 & $13,8 \%$ \\
\hline Actividades fin & 45.21 & $3,3 \%$ & 47.771 & $3,1 \%$ & 68.550 & $4,2 \%$ \\
\hline Actividades profesionales e inmobiliarias & $\$ 122.209$ & $9,0 \%$ & 118.561 & $7,7 \%$ & $\$ 120.742$ & $7,3 \%$ \\
\hline Administración pública & 85.745 & $6,3 \%$ & 89.793 & $5,9 \%$ & $\$ 138.049$ & $8,4 \%$ \\
\hline Enseñanza & 89.604 & $6,6 \%$ & 92.907 & $6,1 \%$ & $\$ 109.168$ & $6,6 \%$ \\
\hline Salud & 64.816 & $4,8 \%$ & 73.304 & $4,8 \%$ & 95.154 & $5,8 \%$ \\
\hline Otros s & 17.98 & $1,3 \%$ & 20.893 & $1,4 \%$ & 23.833 & $1,4 \%$ \\
\hline Valor Agregado Bruto & $\$ 1.359 .018$ & $100 \%$ & $\$ 1.532 .380$ & $100 \%$ & $\$ 1.644 .188$ & $100,0 \%$ \\
\hline
\end{tabular}

Fuente: Cuentas Cantonales, Banco Central del Ecuador

Elaboración: Personal Técnico Observatorio Económico y Social de Tungurahua
En el año 2009 el VAB es de 1'644.188 miles de dólares, de la cual, las cuatro industrias más representativas son: Comercio con el $14,9 \%$, le sigue los servicios de transporte, información y comunicaciones con una participación del 13,8\%, en tercera ubicación esta la construcción con el 11,5\%, y la cuarta posición es el sector de manufactura con el 8,4\%.

La estructura productiva de Tungurahua desde una perspectiva cantonal, los que mayor contribuye al total del VAB provincial son: Ambato (70,7\%), Baños (9,9\%), Pelileo $(7,7 \%)$ y Píllaro $(5,9 \%)$, mientras que con menos participación es Patate $(1,8 \%)$, Quero $(1,4 \%)$, Cevallos $(1,0 \%)$, Tisaleo $(1,0 \%)$ y Mocha $(0,7 \%)$.

Valor Agregado Bruto, Según Cantones

Periodo 2007-2009

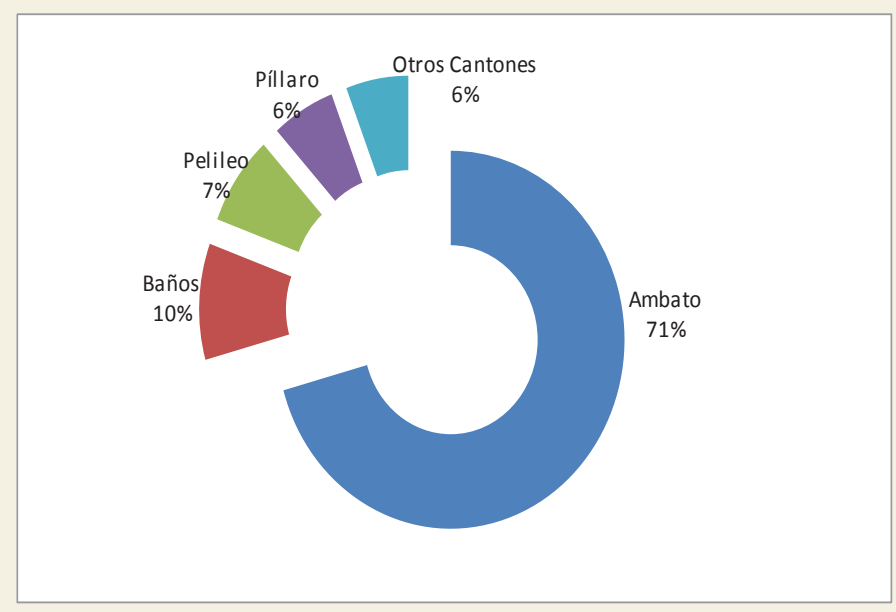

Fuente: Cuentas Cantonales, Banco Central del Ecuador

Elaboración: Personal Técnico Observatorio Económico y Social de Tungurahua

En Tungurahua las industrias o sectores más representativos al valor agregado bruto de cada uno de los nueve cantones son las siguientes: 
INDUSTRARS MÁS REPPRESENTATIUAS AL VALOR AGREEADO BRUTO, SEEUIN BANTÓN

\section{Aĩ̃o 2009}

\begin{tabular}{|c|c|c|}
\hline Centión & $\begin{array}{l}\text { Valor Agregiado Bruto Cen- } \\
\text { tonal miles de uólares }\end{array}$ & Industrias más reppresenteativeas \\
\hline Ambato & 1.162.177 USD & $\begin{array}{l}\text { Comercio }(19,3 \%) \text {, Transpor- } \\
\text { te, información y comunica- } \\
\text { ciones (15\%), Manufactura } \\
(10,8 \%) \text { y Actividades profe- } \\
\text { sionales e inmobiliarias }(10 \%)\end{array}$ \\
\hline Baños & 163.446 USD & $\begin{array}{l}\text { Suministro de electricidad y } \\
\text { de agua }(59,9 \%) \text {, Actividades } \\
\text { de alojamiento y de comi- } \\
\text { das }(9,6 \%) \text {, Transporte, in- } \\
\text { formación y comunicaciones } \\
(5,6 \%) \text { y Construcción }(5,5 \%)\end{array}$ \\
\hline Pelileo & 97.121 USD & $\begin{array}{l}\text { Agricultura, ganadería, sil- } \\
\text { vicultura y pesca ( } 41,3 \%) \text {, } \\
\text { Construcción }(18,7 \%) \text {, Trans- } \\
\text { porte, información y comuni- } \\
\text { caciones }(10 \%) \text { Enseñanza } \\
(9 \%)\end{array}$ \\
\hline Píllaro & 97.121 USD & $\begin{array}{l}\text { Construcción }(42,3 \%) \text {, Trans- } \\
\text { porte, información y comuni- } \\
\text { caciones }(12,4 \%) \text {, Suministro } \\
\text { de electricidad y de agua } \\
(11,4 \%) \text { y Enseñanza }(7,7 \%)\end{array}$ \\
\hline Patate & 29.646 USD & $\begin{array}{l}\text { Agricultura, ganadería, sil- } \\
\text { vicultura y pesca (45\%), } \\
\text { Transporte, información y co- } \\
\text { municaciones (15\%), Cons- } \\
\text { trucción }(11,2 \%) \text { y Adminis- } \\
\text { tración pública }(8,1 \%)\end{array}$ \\
\hline Quero & 23.051 USD & $\begin{array}{l}\text { Agricultura, ganadería, sil- } \\
\text { vicultura y pesca (29,9\%), } \\
\text { Construcción }(23,2 \%), \text { Admi- } \\
\text { nistración pública }(17,1 \%) \text { y } \\
\text { Enseñanza }(13,4 \%)\end{array}$ \\
\hline
\end{tabular}

\begin{tabular}{|l|r|l|}
\hline Tisaleo & 15.893 USD & $\begin{array}{l}\text { Transporte, información y co- } \\
\text { municaciones (22,9\%), Cons- } \\
\text { trucción (21,2\%), Agricultu- } \\
\text { ra, ganadería, silvicultura y } \\
\text { pesca (18,8\%), y Comercio } \\
(10,4 \%)\end{array}$ \\
\hline Cevallos & 15.700 USD & $\begin{array}{l}\text { Transporte, información y } \\
\text { comunicaciones (29,2\%), } \\
\text { Agricultura, ganadería, silvi- } \\
\text { cultura y pesca (20\%), Admi- } \\
\text { nistración pública (12,6\%) y } \\
\text { Manufactura (11,9\%) }\end{array}$ \\
\hline Mocha & 11.140 USD & $\begin{array}{l}\text { Transporte, información y } \\
\text { comunicaciones (33,9\%), } \\
\text { Agricultura, ganadería, silvi- } \\
\text { cultura y pesca (28,5\%), Ad- } \\
\text { ministración pública (13,5\%) } \\
\text { y Construcción (12,4\%) }\end{array}$ \\
\hline
\end{tabular}

Fuente: Cuentas Cantonales, Banco Central del Ecuador

Elaboración: Personal Técnico Observatorio Económico y Social de Tungurahua

Las características productivas de la Provincia de Tungurahua en el año 2009, está determinado por diez sectores, donde su mayor prevalencia dentro de las cuatro actividades con mayor participación de valor añadido a la economía.

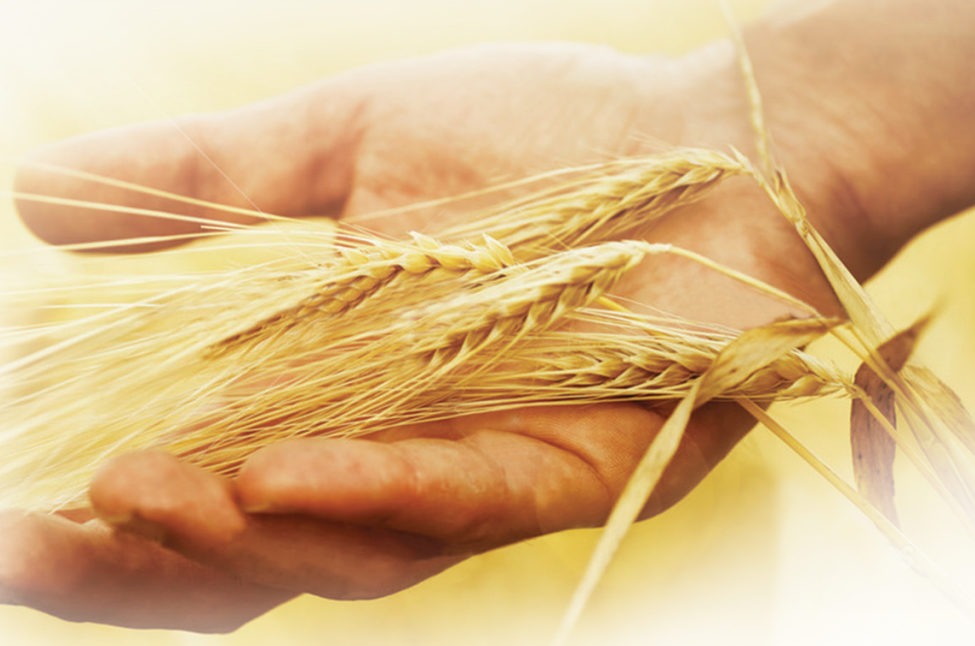




\begin{tabular}{|l|l|}
\multicolumn{1}{l|}{ INDUSTRIA O SECTOR } & CANTONES \\
\hline $\begin{array}{l}\text { Transporte, información y comunica- } \\
\text { ciones }\end{array}$ & $\begin{array}{l}\text { Ambato, Baños, Pelileo, Píllaro, Patate, } \\
\text { Tisaleo, Cevallos y Mocha }\end{array}$ \\
\hline $\begin{array}{l}\text { Construcción } \\
\begin{array}{l}\text { Agricultura, ganadería, silvicultura y y } \\
\text { pesca }\end{array}\end{array}$ & $\begin{array}{l}\text { Baños, Pelileo, Píllaro, Patate, Quero, } \\
\text { Tisaleo y Mocha } \\
\text { Pelileo, Patate, Quero, Tisaleo, Cevallos } \\
\text { y Mocha }\end{array}$ \\
\hline Administración pública & Patate, Quero, Cevallos y Mocha \\
\hline Enseñanza & Pelileo, Píllaro y Quero \\
\hline Comercio & Ambato y Tisaleo \\
\hline Manufactura & Ambato y Cevallos \\
\hline Suministro de electricidad y de agua & Baños y Píllaro \\
\hline $\begin{array}{l}\text { Actividades profesionales e inmobi- } \\
\text { liarias }\end{array}$ & Ambato \\
\hline $\begin{array}{l}\text { Actividades de alojamiento y de co- } \\
\text { midas }\end{array}$ & Baños \\
\hline
\end{tabular}

La información descrita al ser su disponibilidad hasta el año 2009 , sirve como un referente en los procesos de planificación y articulación de políticas públicas orientadas al fortalecimiento del proceso productivo en Tungurahua.

\section{Referencias}

- Banco Central del Ecuador, Información Estadística, Cuentas Nacionales, Regionales y Cantonales. [en línea] disponible en: http://www.bce.fin.ec/index.php/component/k2/ item/293-cuentas-provinciales

- Secretaria Nacional de Planificación y Desarrollo SENPLADES, Sistema Nacional de Información SIN [en línea] disponible en: http://sni.gob.ec/sni territorial/

\section{Observatorio Económico y Social de Tungurahua (OBEST) - Universidad Técnica de Ambato. \\ Econ. Juan Pablo Martínez}

Fuente: Cuentas Cantonales, Banco Central del Ecuador

Elaboración: Personal Técnico Observatorio Económico y Social de Tungurahua
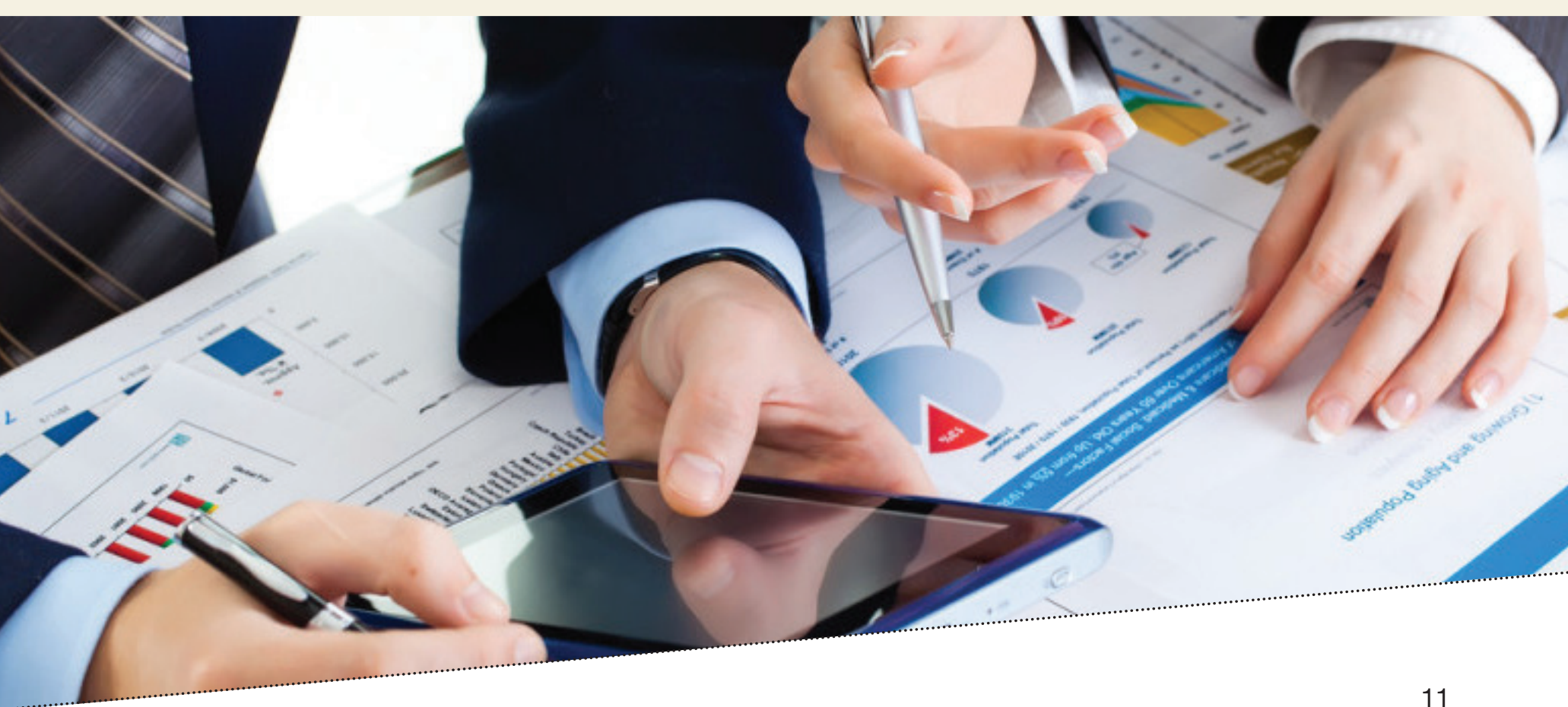